1. GRANT NUMBER: DE-FG22-90PC90292

2. PERIOD COVERED BY REPORT: September 1, 1991 - August 31, 1992

\title{
3. TITLE OF PROPOSAL: ALTERNATIVE FORMULATIONS OF REGENERABLE FLUE GAS CLEANUP CATALYSTS
}

4. NAME OF INSTITUTION: Clark Atlanta University

5. AUTHOR(S) OF REPORT: Drs. Mark B. Mitchell and Mark G. White

\section{DISCLAIMER}

This report was prepared as an account of work sponsored by an agency of the United States Government. Neither the United States Government nor any agency thereof, nor any of their employees, makes any warranty, express or implied, or assumes any legal liability or responsibility for the accuracy, completeness, or usefulness of any information, apparatus, product, or process disclosed, or represents that its use would not infringe privately owned rights. Reference herein to any specific commercial product, process, or service by trade name, trademark, manufacturer, or otherwise does not necessarily constitute or imply its endorsement, recommendation, or favoring by the United States Government or any agency thereof. The views and opinions of authors expressed herein do not necessarily state or reflect those of the United States Government or any agency thereof.

US/DOE Patent Clearance is not required prior to the publication of this document. 


\begin{abstract}
We have used non-aqueous impregnation techniques to prepare an aluminum oxide surface covered with a well-dispersed magnesium oxide layer using magnesium acetylacetonate dihydrate $\left[\mathrm{Mg}(\mathrm{acac})_{2} \cdot 2 \mathrm{H}_{2} \mathrm{O}\right]$ as a precursor. Using lithium acetylacetonate as a precursor, we have begun attempts to prepare a similarly welldispersed surface layer of lithium "oxide." We have generated higher weight loadings of magnesium on alumina by using a Soxhlet extractor to dissolve the sparingly soluble $\mathrm{Mg}(\mathrm{acac})_{2} \cdot 2 \mathrm{H}_{2} \mathrm{O}$ in methanol. With this device we are able to obtain loadings of $\mathrm{MgO}$ on the alumina up to $0.66 \mathrm{wt} / \mathrm{wt} \%$. The precursor samples were examined by diffuse reflectance infrared Fourier transform spectroscopy (DRIFTS) and our results indicate that the complex loses the water of hydration upon adsorption. It appears, however, that the initial form of the complex on the surface is as anhydrous crystallites. Heating the supported precursor under vacuum leads to "melting" of the crystals, which can be observed by DRIFTS. Decomposition of the precursor under nitrogen or air leads to very similar activity when adsorbing $\mathrm{SO}_{2} . \mathrm{SO}_{2}$ uptake appears to be independent of whether $\mathrm{O}_{2}$ is present in the gas stream or not. We have shown that $\mathrm{SO}_{2}$ adsorption increases with $\mathrm{Mg}$-loading on the impregnated aluminas, with 0.85 additional molecules of $\mathrm{SO}_{2}$ adsorbed for each additional $\mathrm{Mg}$ atom (or $\mathrm{MgO}$ molecule) on the surface. We have shown that non-aqueous impregnation leads to samples which are more efficient with regard to $\mathrm{SO}_{2}$ uptake per magnesium atom than aqueous impregnation.
\end{abstract}




\section{INTRODUCTION}

The goal of this project is the development of a superior regenerable sorbent for $\mathrm{SO}_{2} / \mathrm{NO}_{\mathrm{x}}$. The rationale has always been that it may be possible to "tune" the adsorption/desorption behavior of alumina for $\mathrm{SO}_{2} / \mathrm{NO}_{\mathrm{x}}$ with a judicious choice of promoter, and that the surface may be made more active by dispersing the promoters evenly over the substrate surface. We have had good success using magnesium as a promoter for $\mathrm{SO}_{2}$ adsorption and using magnesium acetylacetonate dihydrate $\left[\mathrm{Mg}(\mathrm{acac})_{2}\right.$ $-2 \mathrm{H}_{2} \mathrm{O}$ ] as a precursor. This report summarizes the results reported in earlier quarterly reports, and continues with results we have recently obtained after modifying the atmosphere in which our experiments were being carried out from a reducing atmosphere to an oxidizing one, and with our initial attempts at depositing lithium on the alumina surface.

During this year, we have demonstrated the utility of non-aqueous impregnation techniques for preparing supported $\mathrm{MgO}$ on alumina. Our past reports have demonstrated the improvement in sorption capacity realized when using magnesium as a promoter on an alumina surface relative to a bare alumina surface. We have shown that non-aqueous impregnation in the case of magnesium leads to samples which adsorb more $\mathrm{SO}_{2}$ per magnesium than does aqueous impregnation. We have begun efforts to prepare alumina surfaces doped with lithium, calcium, and sodium using non-aqueous impregnation techniques.

\section{EXPERIMENTAL}

\section{Materials and Preparation}

As mentioned in previous reports, we are investigating several different aluminas as support materials. The Goodfellow alumina which we are using is a particularly pure $\gamma$ alumina $(99.95 \%)$. All of our results reported here are obtained using this alumina.

For the preparation of the $\mathrm{Mg}(\mathrm{acac})_{2}$ impregnated alumina samples, a target loading of the precursor $\left[\mathrm{Mg}(\mathrm{acac})_{2} \cdot 2 \mathrm{H}_{2} \mathrm{O}\right]$ on the substrate was determined, the appropriate amount of the magnesium complex was dissolved in methanol, and the appropriate amount of alumina was added to develop the target loading of the support. The mixture was stirred for four hours and the impregnated alumina separated from the impregnation solution using a Buchner funnel. The solid was air-dried at room temperature and then dried at $90^{\circ} \mathrm{C}$ for 18 hours. Samples were submitted to Applied Technical Services to determine the magnesium content and the carbon and hydrogen content of the samples from the same lots were determined by Atlantic Microlab.

A Soxhlet extraction tube was used in an attempt to generate a higher concentration of magnesium on the alumina supports than was found possible using standard methods. Because $\mathrm{Mg}(\mathrm{acac})_{2} \cdot 2 \mathrm{H}_{2} \mathrm{O}$ is only slightly soluble in methanol, it was felt that the standard method of impregnation, discussed in earlier reports, was limited in 
the amount of complex which could be loaded on to the support surface. It was decided to try another method using a Soxhlet extractor.

A Soxhlet extraction tube is illustrated in Figure 1, and the impregnation method using the Soxhlet extractor is as follows. The alumina to be impregnated was placed with pure solvent (methanol) in the flask below the extraction tube. The $\mathrm{Mg}(\mathrm{acac})_{2} \bullet$ $2 \mathrm{H}_{2} \mathrm{O}$ to be used for impregnation was placed in the porous cup in the Soxhlet extraction tube and a condenser was fitted on top of the extraction tube. When the solvent boils, solvent vapor makes its way up the larger sidearm of the extraction tube, condensing in the condenser, and falling on the $\mathrm{Mg}(\mathrm{acac})_{2} \cdot 2 \mathrm{H}_{2} \mathrm{O}$ in the porous sample cup. The hot solvent then dissolves some of the metal complex. As the liquid level rises in the extraction tube, it finally reaches a level just greater than the level of the elbow in the smaller sidearm of the extraction tube. At this point, the saturated solution is siphoned from the extraction tube and falls into the solvent/alumina mixture in the flask. As the cycle is repeated, pure solvent vapor again begins condensing over the metal complex to be dissolved, and the process continues. The fact that pure solvent continually washes over the material to be dissolved is what gives this process its potential to generate weight loadings on alumina using methanol as a solvent that are greater than would otherwise be possible.

\section{$\mathrm{SO}_{2}$ Adsorption on Alumina and Impregnated Alumina}

The $\mathrm{SO}_{2}$ adsorption/desorption experiments on alumina and $\mathrm{Mg}$-impregnated alumina were carried out in the Perkin-Elmer thermal gravimetric analyzer (TGA) as follows. The sample was first pretreated to decompose the precursor complex $\left[\mathrm{Mg}(\mathrm{acac}) 2 \cdot 2 \mathrm{H}_{2} \mathrm{O}\right]$, if appropriate, and to dehydrate and partially dehydroxylate the solid. Approximately $5 \mathrm{mg}$ of the solid was loaded into a quartz crucible and placed in the TGA. In the TGA, the sample was kept under flowing $\left(150 \mathrm{~cm}^{3} / \mathrm{min}\right)$ nitrogen or a 50:50 oxygen:nitrogen mixture. We have determined empirically that decomposition of the precursor to yield the promoted alumina proceeds more effectively in oxygen or an oxygen/nitrogen mixture than in nitrogen alone. We observed that decomposition in pure nitrogen yielded a product which appeared black on the surface. However, decomposition in oxygen yielded a product that was completely white. So all of the decompositions are carried out in the 1:1 oxygen:nitrogen mixture.

Pretreatment. The sample was heated from an initial temperature of $40^{\circ} \mathrm{C}$ to a final temperature of $550^{\circ} \mathrm{C}$ at a rate of $20^{\circ} \mathrm{C} / \mathrm{min}$ and then allowed to cool to the initial temperature, all carried out under the flowing gas atmosphere mentioned above. The initial weight of the sample was taken after cooling to $40^{\circ} \mathrm{C}$.

$\underline{\mathrm{SQ}}_{2}$ Adsorption. $\mathrm{SO}_{2}$ adsorption was carried out isothermally at $40^{\circ} \mathrm{C}$. The gas mixture used for the $\mathrm{SO}_{2}$ adsorption was generated by mixing a pure $\mathrm{N}_{2}$ flow with a gas mixture containing $0.22 \% \mathrm{SO}_{2}$ with the balance $\mathrm{N}_{2}$. A $1: 1$ mixture of these two gases gave a $\mathrm{SO}_{2}$ concentration over the sample of $1,100 \mathrm{ppm}$. In several experiments, the adsorption mixture was adjusted to contain $20 \%$ oxygen. The sulfur dioxide-containing gas contacted the sample for 20 minutes and was followed by an isothermal purge of pure $\mathrm{N}_{2}$ 
gas for 25 minutes to remove any loosely held $\mathrm{SO}_{2}$. The flow rate of the $\mathrm{SO}_{2}$-containing gas and the purge over the sample was $150 \mathrm{~cm}^{3} / \mathrm{min}$. The weight of adsorbed $\mathrm{SO}_{2}$ was calculated by subtracting the initial weight from the weight of the sample after the isothermal purge.

$\mathrm{SO}_{2}$ Desorption, $\mathrm{SO}_{2}$ desorption was carried out in a $\mathrm{N}_{2}$ or $\mathrm{O}_{2} / \mathrm{N}_{2}$ flow at 150 $\mathrm{cm}^{3} / \mathrm{min}$. The sample was heated from $40^{\circ} \mathrm{C}$ to $550^{\circ} \mathrm{C}$ at a rate of $20^{\circ} \mathrm{C} / \mathrm{min}$ and was allowed to cool to room temperature. The final weight of the sample was measured after the sample had cooled to $40^{\circ} \mathrm{C}$.

The adsorption/desorption cycles were repeated twice for each sample for a total of three cycles measured for each sample.

\section{Infrared Spectroscopy}

For the infrared studies, we used a DRIFTS optical accessory from Harrick Scientific Corporation, DRA-2CO. A Nicolet 510 (an extensively upgraded 5-DXB) with a new data station and a mercury-cadmium-telluride (MCT) detector was the FT-IR used in these experiments. The samples were prepared by physically mixing the impregnated alumina $10 \%$ by weight with $\mathrm{KBr}$. The powder mixture was loaded into the DRIFTS sample cup and the surface carefully leveled with a spatula.

For the controlled-environment studies, a controlled environment cell from Harrick Scientific, HVC-DR2, designed specifically for use with the diffuse reflectance optical accessory, was used.

\section{RESULTS AND DISCUSSION}

\section{Precursor Characterization}

We were able to generate higher weight loadings of magnesium on the alumina support by using the Soxhlet device. With this device we were able to generate loadings of $\mathrm{MgO}$ on the alumina (after decomposition of the precursor complex) up to $0.66 \mathrm{wt} \%$ $\mathrm{MgO}$. The two highest weight loadings were obtained using the Soxhlet extraction device.

Atomic Analyses. The Mg weight loading on the support (analysis performed by Applied Technical Services, Marietta, GA) vs the impregnation solution $\mathrm{Mg}$ concentration is illustrated graphically in Figure 2. The two highest weight loadings were obtained using the Soxhlet extraction device.

A plot of the carbon loading (analysis performed by Atlantic Microlab, Norcross, GA) vs Mg loading (analysis performed by Applied Technical Services, Marietta, GA) is shown in Figure 3. These results include the higher weight loadings obtained using the Soxhlet extractor and the new Mg-loading values. The slope of the line is 10.01, virtually identical to what is expected from an intact precursor complex (10.0). This 
carbon to metal ratio suggests that no ligands are lost from the samples during the impregnation with methanol.

Infrared Results. Our efforts to prepare a sample of alumina impregnated with magnesium acetylacetonate dihydrate included the use of both methanol and acetonitrile as solvents. Our experience with copper acetylacetonate as a precursor showed us that acetonitrile was a superior solvent for that particular species. However, the magnesium precursor was determined to be virtually insoluble in acetonitrile and, as a result, methanol was used as the solvent for impregnation. The efficiency of the impregnation procedure was determined using metals analysis after impregnation of the samples. The magnesium results indicated that the efficiency of the impregnation procedure was not as high as we had observed impregnating copper acetylacetonate on silica, such that even using the Soxhlet extraction device as mentioned in our previous report we were only able to obtain what we calculated was about one-half of a monolayer coverage. (See Figure 1). As discussed in our last report, the slope of the line in Figure 1, 0.17, is an indicator of the impregnation efficiency and can be compared to a value of 0.53 obtained for a similar determination of impregnation efficiency for copper acetylacetonate on silica from acetonitrile solution. Carbon analysis on the magnesium-doped alumina samples gave a C:Mg ratio of 10:1, indicating that ligands were not lost from the complex during adsorption.

In our previous reports, we had been assuming that the magnesium acetylacetonate was covering the surface of the alumina in much the same way that we had observed for copper on silica, that is, as an evenly-distributed layer. Our initial interpretation of the infrared spectra supported this conclusion. However, after further study of the material including in situ infrared investigations while heating under vacuum and in air and $\mathrm{SO}_{2}$, we have come to the conclusion that the initial interpretation was in error, and that in fact the spectra indicate the formation of surface crystallites of the anhydrous precursor, which subsequently "melts" to cover the surface on heating under vacuum.

Our initial conclusion regarding the infrared spectra had been based on the major differences between the spectrum of the parent $\mathrm{Mg}(\mathrm{acac})_{2} \cdot 2 \mathrm{H}_{2} \mathrm{O}$ complex and that of the supported species, and the similarity between the spectrum of the supported magnesium complex and that of a sub-monolayer coverage of copper acetylacetonate on silica. (See Figure 4-6). However, upon heating the spectrum of the supported magnesium complex evolved into the spectrum shown in Fig. 7. We had initially assumed that the strong band at $1526 \mathrm{~cm}^{-1}$ in the spectrum of the magnesium complex corresponded to the antisymmetric in-plane $\mathrm{C}-\mathrm{C}-\mathrm{C}$ bend of the ligand, and that no overtone of the $\mathrm{C}-\mathrm{H}$ outof-plane bending motion was present in the spectrum of the magnesium complex. In previous studies, we have found that the absence of the overtone $\mathrm{C}-\mathrm{H}$ out-of-plane bending motion indicates the absence of multiple layers for $\mathrm{Cu}(\mathrm{acac})_{2}$ on silica. ${ }^{1}$ On heating, however, the intensity of the $1526 \mathrm{~cm}^{-1}$ band of the magnesium complex on alumina decreased relative to that of other bands, which led us to investigate the spectrum in more detail. What we determined was that the $1526 \mathrm{~cm}^{-1}$ band is, in fact, the overtone of the $\mathrm{C}-\mathrm{H}$ out-of-plane motion for the magnesium complex, the 
fundamental is at $765 \mathrm{~cm}^{-1}$. Our interpretation of the results now is that the $\mathrm{Mg}(\mathrm{acac})_{2}$ complex is forms initially on the surface as small crystals of the anhydrous complex. This could explain why it is so difficult to form high loadings of the magnesium complex on the surface.

Since Figures 6 and 7 are spectra of the same sample, the only difference being heating of the sample, a ratio of these spectra provides significant insight with regard to changes in the surface structure. Such a ratio is shown in Figure 8 . The ratio of the corresponding single beam spectra has been converted to absorbance units, such that upward going peaks correspond to spectral features "lost" as a result of heating, downward going peaks correspond to spectral features "gained" as a result of heating. What is noticeable about this spectrum, aside from what appears to be a broad gain in intensity which may be accounted for by baseline drift, is that upon heating spectral intensity has been lost from the peak absorption regions and has been gained in the wings of the absorption bands. This change in the spectrum of the heated sample remains after cooling to room temperature. An integration of the spectral intensity can be carried out over the frequency range shown in Figure 8 in an attempt to show little or no net loss of infrared absorption intensity, but the results obtained are very sensitive to the baseline correction and the limits are used for the integration, so this discussion will remain qualitative.

What appears to have happened as a result of heating is a "spreading out" of the spectral intensity. Upon heating, many of the complexes migrate from a set of sites which are all very similar and provide similar interactions with the complex to sites which do not have a well-defined interaction with the complex. Crystalline materials have a set of well-defined absorption frequencies and associated linewidths, and each linewidth is a function of the distribution of crystal sites in which the chromophore is found. One process which would give rise to the observed change in the spectra is a migration of the complexes from small crystals or multilayer structures to sites on the alumina surface. The alumina surface sites do not provide a well-defined environment for molecules of the complex since the surface atomic spacing does not match that of the complex. There are many more micro environments or adsorption sites present on the alumina surface than in the crystal, and this distribution of sites leads to inhomogeneous broadening of the absorption bands, similar to that seen for the $\mathrm{Cu}(\mathrm{acac})_{2}$ complex on the silica surface. Additional evidence in support of this conclusion can be found in another region of this spectrum. Figure 9 is an expanded view of Figure 8 and what is evident is that one of the peaks "lost" as a result of heating is the broad absorption at $1000 \mathrm{~cm}^{-1}$. This band is due to the alumina substrate. As the magnesium complex migrates to the alumina surface, the extended film of the complex acts as a dielectric layer, reflecting light which was previously absorbed by the alumina substrate, reducing the observed absorbance by alumina. 


\section{$\mathrm{SO}_{2}$ Adsorption on Alumina and $\mathrm{Mg}$-Impregnated Alumina}

Figure 10 shows the results of the $\mathrm{SO}_{2}$ adsorption/desorption experiments on six alumina samples with weight loadings of magnesium (analyzed using atomic absorption by Applied Technical Services, Inc. of Marietta, GA) that varied from $37 \mu \mathrm{mol} \mathrm{Mg} / \mathrm{g}$ $\mathrm{Al}_{2} \mathrm{O}_{3}$ to $164 \mu \mathrm{mol} \mathrm{Mg} / \mathrm{g} \mathrm{Al}_{2} \mathrm{O}_{3}$. Each bar in the figure represents a percent weight change for a particular step, either adsorption or desorption, and all changes are shown as positive changes so that they may be compared easily. The results from the bar graphs are summarized in Figure 11 which illustrates the change in $\mathrm{SO}_{2}$ capacity as a function of $\mathrm{Mg}$ loading, and includes our measured value for the adsorption of $\mathrm{SO}_{2}$ by pure alumina $\left(1.65 \mathrm{wt} / \mathrm{wt} \% \mathrm{SO}_{2}\right)$. The $\mathrm{SO}_{2}$ capacity is taken in the most conservative way, that is, the amount of $\mathrm{SO}_{2}$ either adsorbed or desorbed during one cycle from a particular sample. As can be seen from Figure 11, the capacity of the impregnated alumina increases in a linear fashion with $\mathrm{Mg}$ loading. The slope of the line is found to be 1.35 , which means that a $1 \%$ increase in $\mathrm{Mg}$ weight loading results in a $1.35 \%$ increase in $\mathrm{SO}_{2}$ capacity. Converting these percent values to molar values yields the result that every molecule of $\mathrm{MgO}$ on the surface yields an additional 0.85 molecules of $\mathrm{SO}_{2}$ adsorbed.

Effect of $\mathrm{O}_{2}$ on Desorption. The $\mathrm{SO}_{2}$ adsorption on the highest weight loading sample $\left(165 \mu\right.$ moles $\left./ \mathrm{g} \mathrm{Al}_{2} \mathrm{O}_{3}\right)$ is shown in Figure 12 for adsorption at $40^{\circ} \mathrm{C}$ at $1100 \mathrm{ppm} \mathrm{SO}_{2}$ in nitrogen. The difference between the two sets of bars in Figure 12 is that in one set the desorption step was carried out in pure nitrogen, in the other set the desorption step was carried out in the $20 \% \mathrm{O}_{2}+80 \% \mathrm{~N}_{2}$ mixture. The height of the bar is proportional to the amount of $\mathrm{SO}_{2}$ adsorbed or desorbed during the temperature programmed desorption (TPD). The legend discriminates between samples prepared by thermal treatment in nitrogen only or in a nitrogen/oxygen mixture. A similar experiment using the alumina sample with the next lower Mg-loading (131 $\mu$ moles $\left.\mathrm{Mg} / \mathrm{g} \mathrm{Al}_{2} \mathrm{O}_{3}\right)$ was carried out, and the results from these two experiments are included in Figure 13, along with the earlier results from Figure 11. For these two samples, the desorption atmosphere does not appear to have an effect on the regeneration of the sample.

The data from Figure 13 indicate that the $\mathrm{SO}_{2}$ pickup increases by $1.35 \mathrm{wt} \%$ $\mathrm{SO}_{2} / \mathrm{wt} \% \mathrm{MgO}$. This incremental $\mathrm{SO}_{2}$ pickup corresponds to roughly $0.96 \mathrm{SO}_{2}$ molecules per $\mathrm{Mg}$ ion present in the sample, which suggests that the dispersion of the $\mathrm{MgO}$ in the alumina has a dispersion of $96 \%$. Moreover, this dispersion of $\mathrm{MgO}$ does not sinter for heat treatments to $550^{\circ} \mathrm{C}$, the temperatures normally encountered during the TPD.

Effect of $\mathrm{Q}_{2}$ on Adsorption. Additional adsorption tests (Table 1) were completed for which the alumina sample with the highest loading of $\mathrm{Mg}\left(165 \mu\right.$ moles/g $\left.\mathrm{Al}_{2} \mathrm{O}_{3}\right)$ was exposed to a $\mathrm{SO}_{2}$ adsorption mixture containing $1100 \mathrm{ppm} \mathrm{SO} 2,20 \mathrm{~mol} \% \mathrm{O}_{2}$, with the balance nitrogen. This adsorption was followed by TPD in either pure $\mathrm{N}_{2}$ or a $20 \mathrm{~mol} \%$ $\mathrm{O}_{2}$ in $\mathrm{N}_{2}$ mixture. The goal of these studies was to evaluate the effect of oxygen on the adsorption/desorption properties of the $\mathrm{MgO} /$ alumina. These data show only a slight enhancement of the initial adsorption of $\mathrm{SO}_{2}$ as a result of adding oxygen to the 
adsorption mixture (2.89 and 2.96 vs $2.60 \mathrm{wt} / \mathrm{wt} \% \quad \mathrm{SO}_{2}$ ). However, subsequent desorption by heating in nitrogen or oxygen shows incomplete desorption of the $\mathrm{SO}_{2}$ with the resulting lower adsorption in following cycles. For example, the average reversible adsorption of $\mathrm{SO}_{2}$ in these tests was $2.36-2.46 \mathrm{wt} / \mathrm{wt} \% \mathrm{vs} 2.60 \mathrm{wt} / \mathrm{wt} \%$ in previous tests for which oxygen was not present. Subsequent testing with added oxygen during $\mathrm{SO}_{2}$ adsorption will be necessary to make the effects of added oxygen quantitative.

TABLE 1. $\mathrm{SO}_{2}$ ADSORPTION/DESORPTION RESULTS

DECOMPOSITION: 50\% NITROGEN,50\% OXYGEN ADSORPTION: $1100 \mathrm{ppm} \mathrm{SO}_{2}, 20 \%$ OXYGEN, BALANCE NITROGEN

DESORPTION: $100 \%$ NITROGEN

\begin{tabular}{cccc} 
Sample & Weight (mg) & Weight Change (mg) & \% Change \\
\cline { 2 - 4 } After Decomposition & 1.4068 & - & - \\
First Adsorption & 1.4474 & 0.0406 & 2.89 \\
First Desorption & 1.4148 & 0.0326 & 2.32 \\
Second Adsorption & 1.4428 & 0.0280 & 1.99 \\
Second Desorption & 1.4116 & 0.0312 & 2.22 \\
Third Adsorption & 1.4446 & 0.0330 & 2.35 \\
Third Desorption & 1.4108 & 0.0338 & 2.40 \\
AVERAGE & - & - & 2.36
\end{tabular}

DESORPTION: 20\% OXYGEN, BALANCE NITROGEN

\begin{tabular}{cccc} 
Sample & Weight (mg) & Weight Change (mg) & \% Change \\
\cline { 2 - 3 } After Decomposition & 2.2782 & - & - \\
First Adsorption & 2.3456 & 0.0674 & 2.96 \\
First Desorption & 2.2862 & 0.0594 & 2.61 \\
Second Adsorption & 2.3411 & 0.0549 & 2.41 \\
Second Desorption & 2.2914 & 0.0497 & 2.18 \\
Third Adsorption & 2.3481 & 0.0567 & 2.49 \\
Third Desorption & 2.2996 & 0.0485 & 2.13 \\
AVERAGE & - & - & 2.46
\end{tabular}

Samples prepared by aqueous impregnation of the alumina from solutions of magnesium carbonate (B7 in Figure 13) were examined for $\mathrm{SO}_{2}$ adsorption in $\mathrm{SO}_{2} / \mathrm{N}_{2}$. These samples were heated before exposure to $\mathrm{SO}_{2}$ by the same procedure used for the materials prepared from $\mathrm{Mg}(\mathrm{acac})_{2} \bullet 2 \mathrm{H}_{2} \mathrm{O}$. These adsorption data are shown in Figures 13 and 14 for comparison with the adsorption data from samples prepared using nonaqueous impregnation with the magnesium acetylacetonate. The preliminary results suggest that the material prepared using aqueous impregnation pick up about 0.53 
molecules of $\mathrm{SO}_{2}$ per $\mathrm{Mg}$. If we interpret these data in terms of metal ion dispersion, only about $53 \%$ of the $\mathrm{Mg}$ ions are available for $\mathrm{SO}_{2}$ adsorption. Several more samples prepared using aqueous impregnation need to be investigated to clarify this relationship.

\section{Preparation of Supported Lithium Acetylacetonate}

The promising results from the magnesium system led us to investigate the preparation and characterization of supported group IA metal oxides on alumina. As initial studies, we investigated the solubility of $\mathrm{Li}(\mathrm{acac})$ in methanol and acetonitrile in order to prepare $\mathrm{Li}$ on alumina using the acetylacetonate precursor.

Electrical Conductivity Tests. The literature of the group IA metal acetylacetonate complexes suggests that these metal complexes dissociate in protic solvents such as methanol to produce $\mathrm{Li}^{+}$and (acac)- In the earlier work with $\mathrm{Mg}(\mathrm{acac})_{2} \bullet 2 \mathrm{H}_{2} \mathrm{O}$, we dissolved this metal complex in methanol to produce the precursor, and have used acetonitrile in the past as a solvent for $\mathrm{Cu}(\mathrm{acac})_{2}$. We wanted to investigate the solubility of the lithium acetylacetonate precursor in these two solvents and also needed to determine the extent of the dissociation reaction:

$$
\mathrm{Li}(\mathrm{acac}) \leftrightarrow \mathrm{Li}^{+}+(\mathrm{acac})^{-}
$$

If the dissociation is extensive, the electrical conductivity of the system should be much greater than that observed for a non-dissociating complex such as $\mathrm{Cu}(\mathrm{acac})_{2}$.

Conductivity tests were performed using both lithium and copper acetylacetonate complexes and a lithium salt $\left(\mathrm{LiClO}_{4}\right)$ dissolved in the two chosen solvents (methanol and acetonitrile). The results of these tests are shown in Table 2. Blank solvents showed very low conductivities of 0.73 and $0.56 \mu$ Siemens for methanol and acetonitrile, respectively. The Siemen is the unit of conductivity equal to $1 / \mathrm{ohm}\left(\mathrm{ohm}^{-1}\right)$. For $\mathrm{Cu}(\mathrm{acac})_{2}$, the conductivity of a $153 \mu \mathrm{mol} / \mathrm{ml}$ in methanol was measured to be $185 \mu$ Siemens, and the conductivity of the same concentration in acetonitrile was measured to be $230 \mu$ Siemens. In contrast, the conductivity of a $376 \mu \mathrm{mol} / \mathrm{ml}$ solution of lithium perchlorate in methanol was measured to be $8,800 \mu$ Siemens, and the same concentration in acetonitrile gave a conductivity of $12,000 \mu$ Siemens.

TABLE 2. RESULTS OF ELECTRICAL CONDUCTIVITY TESTS

\begin{tabular}{ccc} 
Sample & Conductivity (uSiemens) \\
\cline { 3 - 3 } Blank & Methanol Solvent & 0.73 \\
$\mathrm{Li}(\mathrm{acac})$ & 2,130 \\
$\mathrm{Cu}(\mathrm{acac})_{2}$ & & 185 \\
$\mathrm{Li}\left(\mathrm{ClO}_{4}\right)$ & & 8,800 \\
& & \\
Blank & Acetonitrile Solvent & 0.56 \\
$\mathrm{Li}(\mathrm{acac})$ & & 3.3 \\
$\mathrm{Cu}(\mathrm{acac})_{2}$ & & 230 \\
$\mathrm{Li}\left(\mathrm{ClO}_{4}\right)$ & 12,000
\end{tabular}


These standards now allow us to interpret the results for $\mathrm{Li}(\mathrm{acac})$ in methanol and acetonitrile. A $377.4 \mu \mathrm{mol} / \mathrm{ml}$ solution in methanol gave a conductivity of $2130 \mu$ Siemens, whereas a saturated solution of $\mathrm{Li}(\mathrm{acac})$ in acetonitrile gave a conductivity of $3.3 \mu$ Siemens. Li(acac) does not readily dissolve in acetonitrile and the low conductivity may be a result of this fact rather than a reflection of a non-dissociative complex. These results suggest that the $\mathrm{Li}(\mathrm{acac})$ dissociates in methanol and the resultant supported adsorbent may show a surface morphology containing $\mathrm{Li}$ ions and chelated $\mathrm{Li}$.

C/Li Stoichiometry. The samples prepared in methanol were submitted for carbon and lithium analysis. The results shown in Figure 15 show that the $\mathrm{C} / \mathrm{Li}$ ratio (1.6) is less than what is predicted for the parent complex $(\mathrm{C} / \mathrm{Li}=5)$. These elemental analyses suggest that the supported precursor is a mixture of $\mathrm{Li}$ ions and chelated $\mathrm{Li}$, presumably $\mathrm{Li}(\mathrm{acac})$.

\section{STUDENT PARTICIPATION}

The graduate student working on the project, Willer Pos, left suddenly at the beginning of September, 1991, after working very effectively during the summer. This was a serious loss, since our graduate student population at Clark Atlanta University is relatively low, and no other students were available to take his place at that time. An undergraduate student, sponsored by an NSF Research Experiences for Undergraduates grant during the Summer of 1992, participated in this project and did some of the infrared characterization of the $\mathrm{Mg}(\mathrm{acac})_{2}$ precursor on alumina. Sumitrananda $\mathrm{N}$. $\mathrm{R}$. Rao, a graduate student in Dr. White's lab at Georgia Tech, has performed the bulk of the thermogravimetric characterization.

A new graduate student from Clark Atlanta University, Emmanuel A. Waddell, Jr., an African-American student with an undergraduate degree from Morehouse College, will participate on this project during the coming year.

\section{PROBLEMS}

During the past year we have had a number of setbacks. These include the sudden departure of the promising graduate student who was working on this project and the loss of our laboratory for two-and-a-half months due to a serious roof leak. Our initial results on $\mathrm{SO}_{2}$ adsorption using infrared spectroscopy were not successful due to problems we were having with our detector. Because of serious access problems we were having with the FT-IR we were using, we decided to fix/upgrade a departmental FT-IR, with the understanding that we have priority access to that instrument. We also moved our laboratory in order to avoid the roof problems which had shut us down. All of these problems, the most serious being the loss of the student, negatively impacted our ability to generate results in the infrared spectroscopic aspects of this project. The new graduate student, is a welcome addition to the project, and we expect to see significant progress in the spectroscopic area of the investigation during the next year. 


\section{FUTURE WORK}

Future work will involve the further characterization by DRIFTS of the supported precursor complex, and the in situ study of the decomposition of the complex and adsorption of $\mathrm{SO}_{2}$. We anticipate beginning the impregnation of alumina with a $\mathrm{Na}$ (acac) and $\mathrm{K}(\mathrm{acac})$ in the near future, with the aim of carrying out non-aqueous impregnation of the alumina with these alkali metals. $\mathrm{SO}_{2}$ adsorption results from these materials will be directly comparable with standard impregnation techniques for sodium and potassium using aqueous methods.

\section{REFERENCES}

1) Kenvin, J. C., White, M. G., Mitchell, M. B. Langmuir, 1991, 7, 1198. 


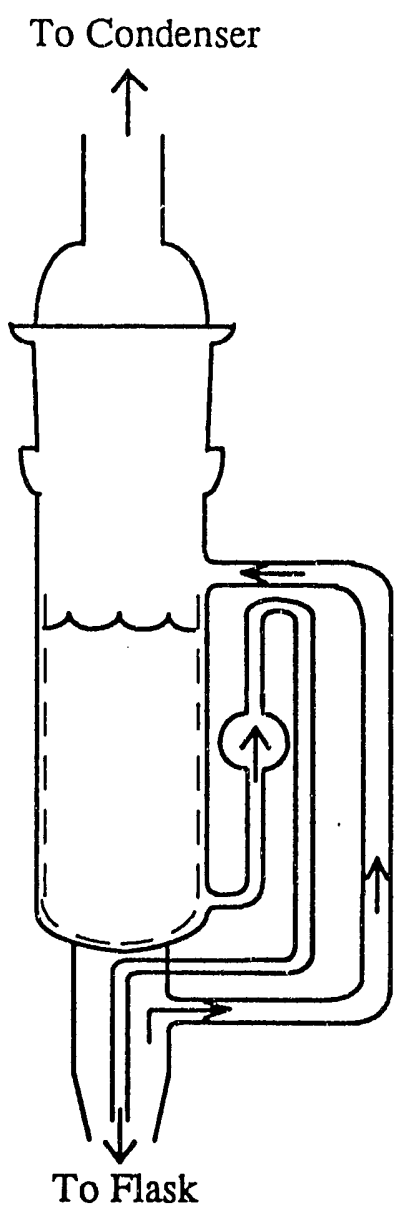

Figure 1. Diagram of a Soxhlet Extraction Apparatus 


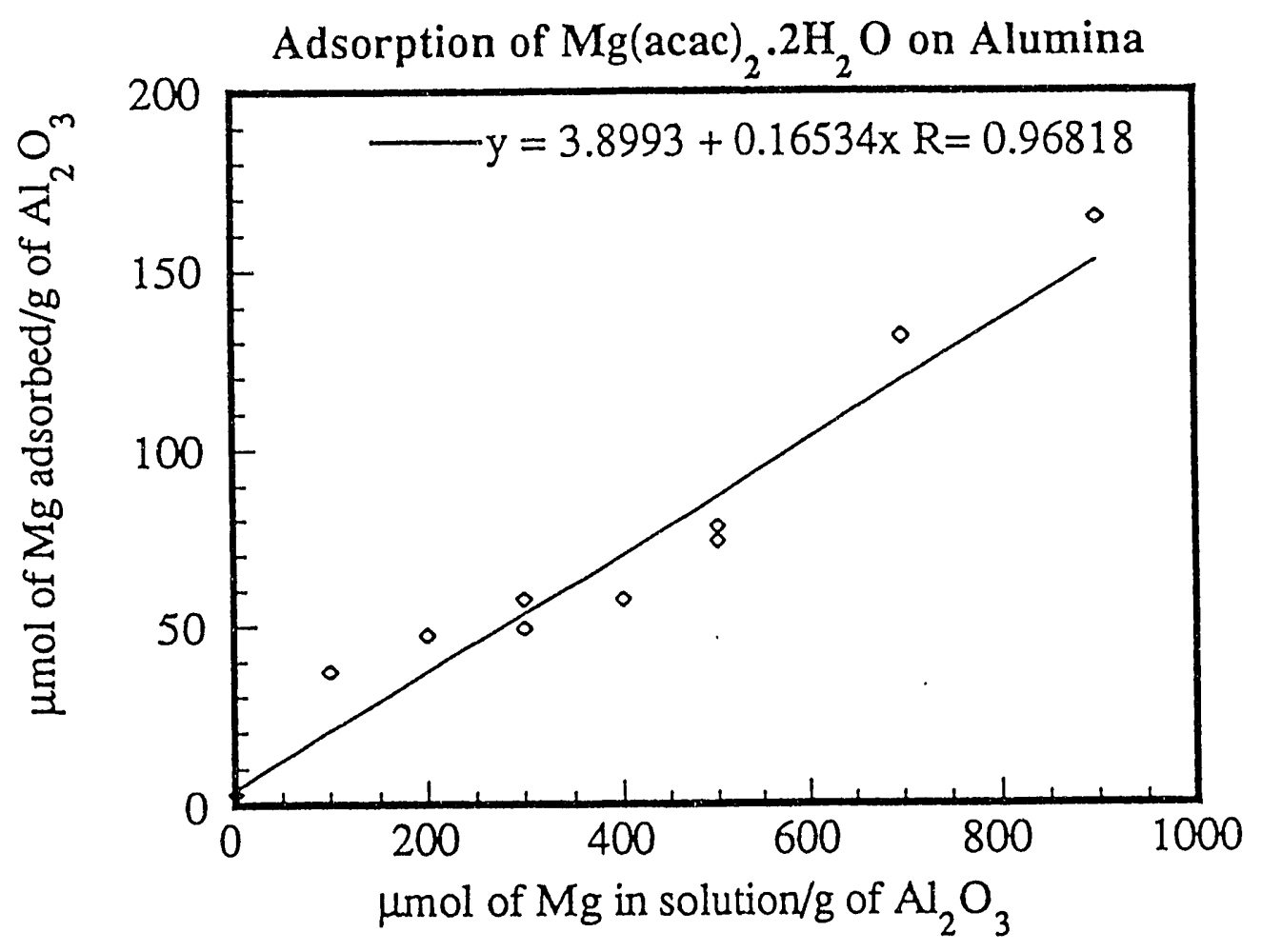

Figure 2. Plot of the adsorption of $\mathrm{Mg}(\mathrm{acac})_{2} \bullet 2 \mathrm{H}_{2} \mathrm{O}$ from methanol solution onto the alumina support. This plot includes corrected results for $\mathrm{Mg}$ loading. The two highest weight loadings were generated using the Soxhlet extractor. 


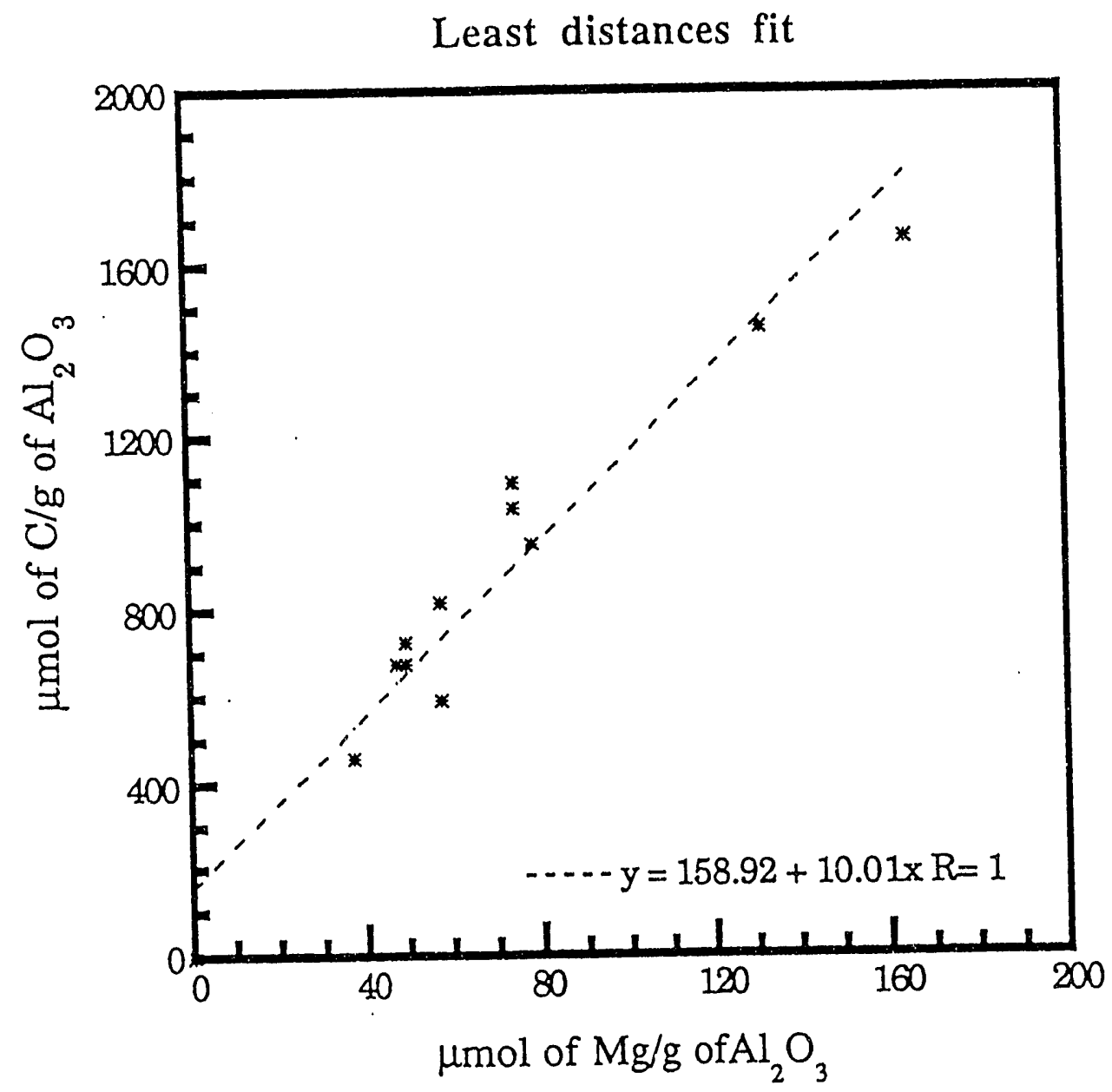

Figure 3. Plot of the measured carbon content vs measured magnesium content for the impregnated alumina samples. 


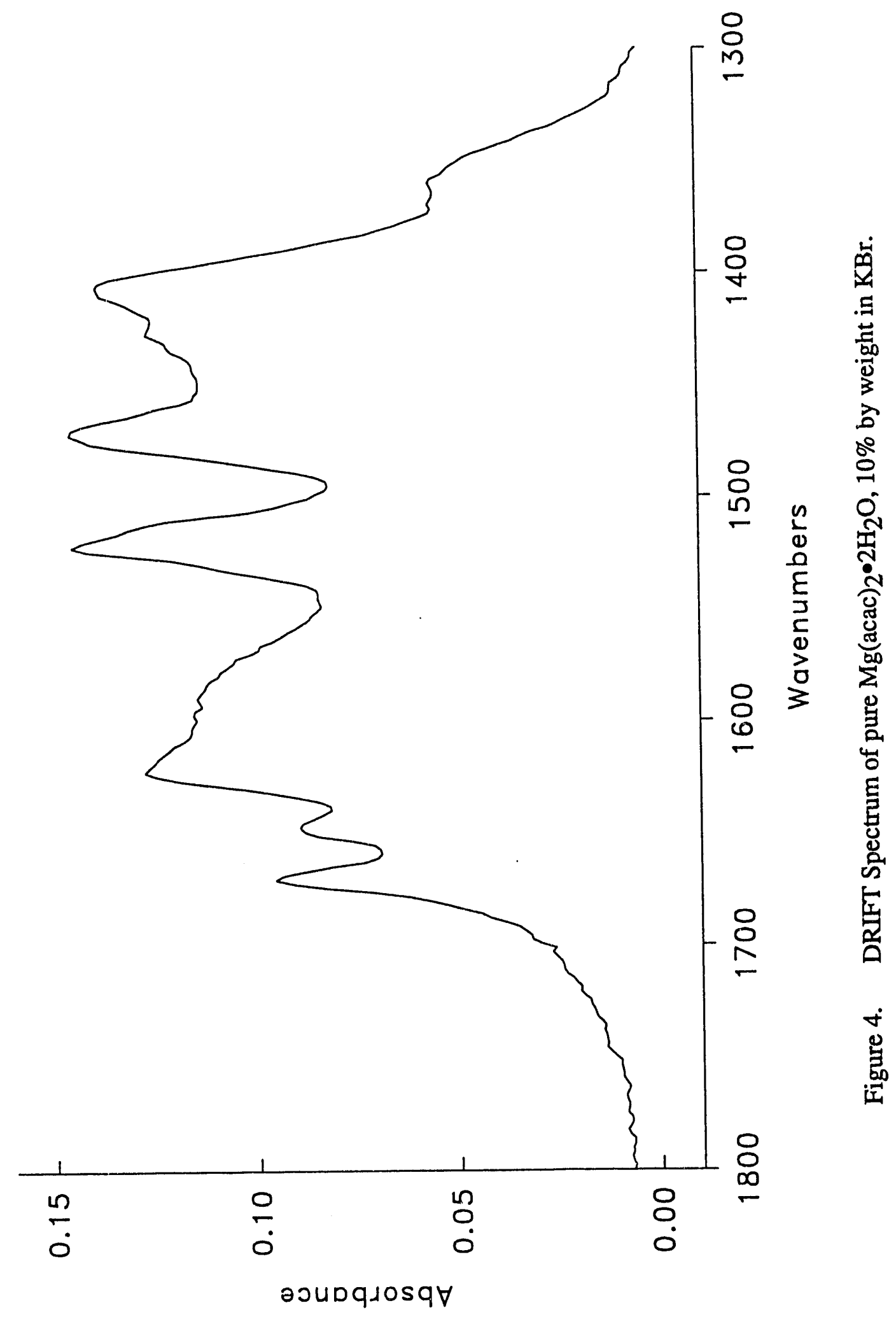




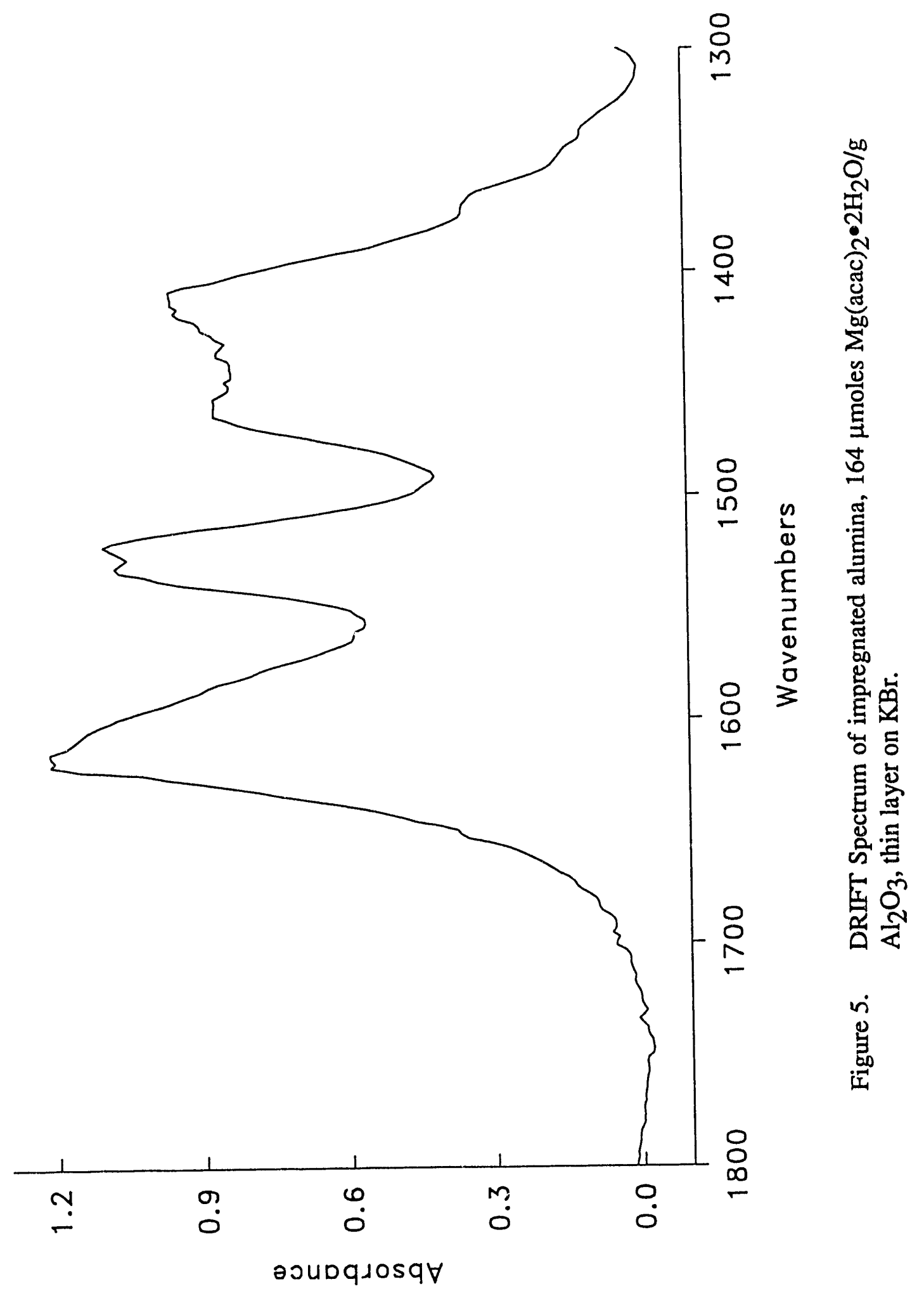




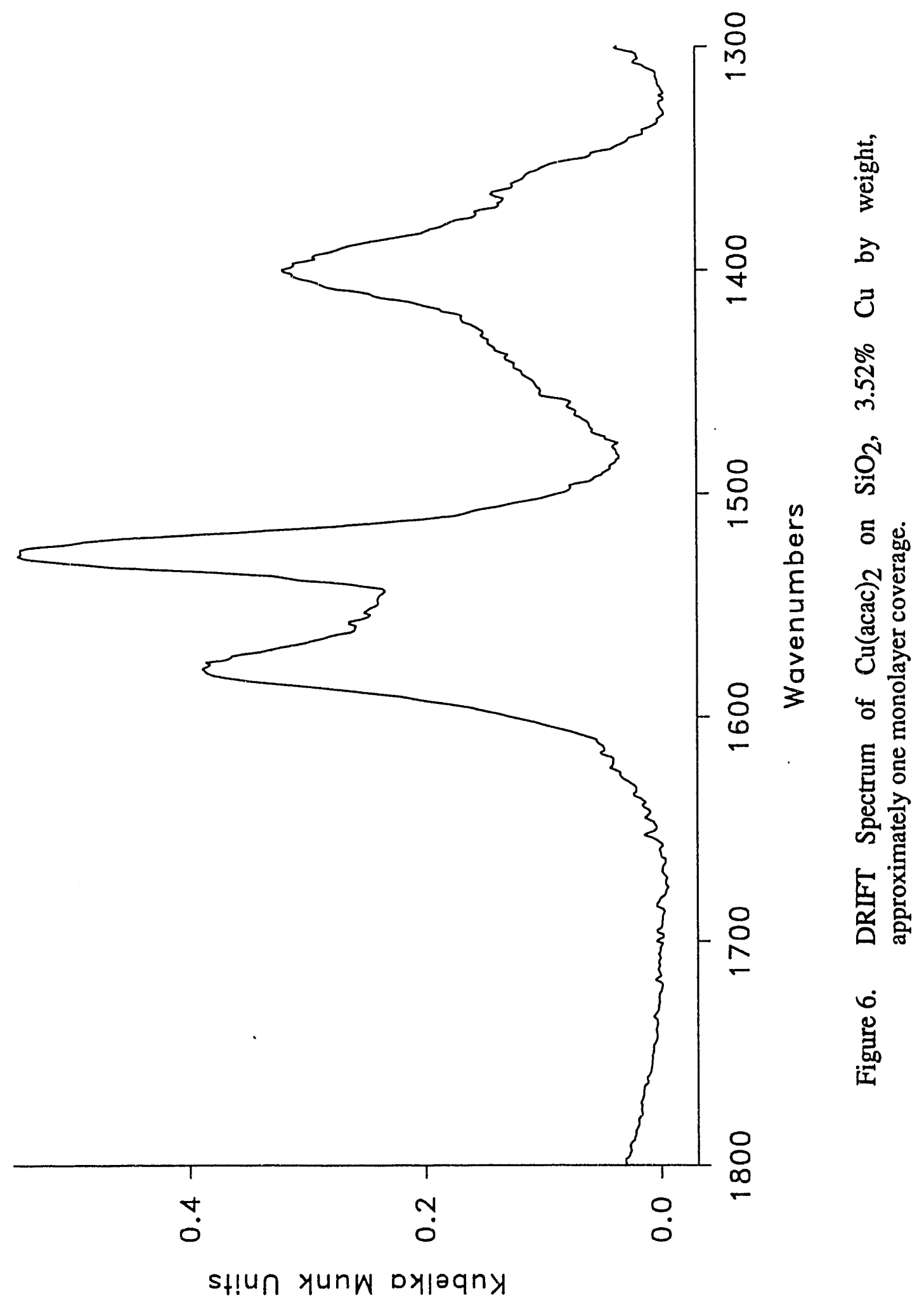




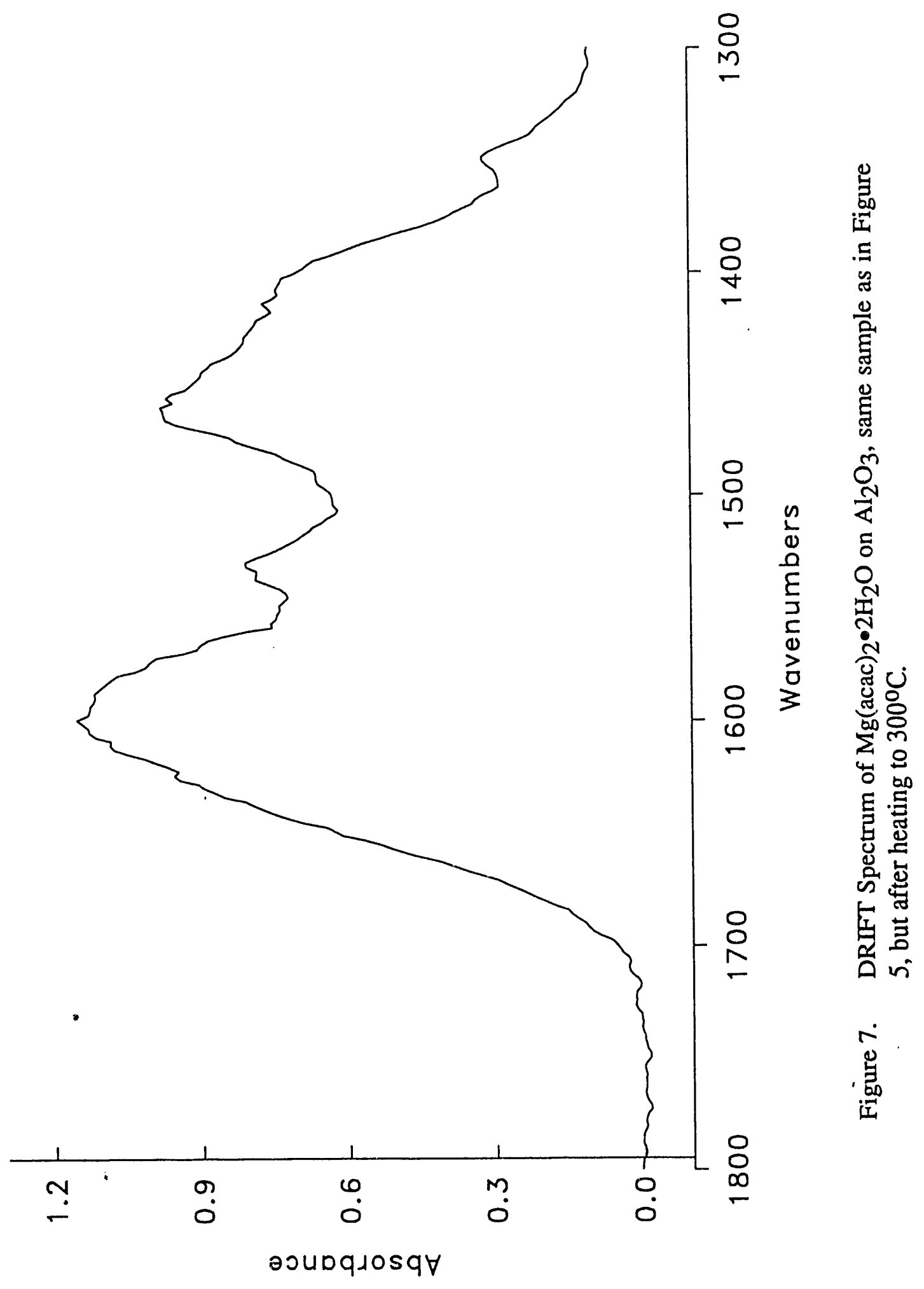




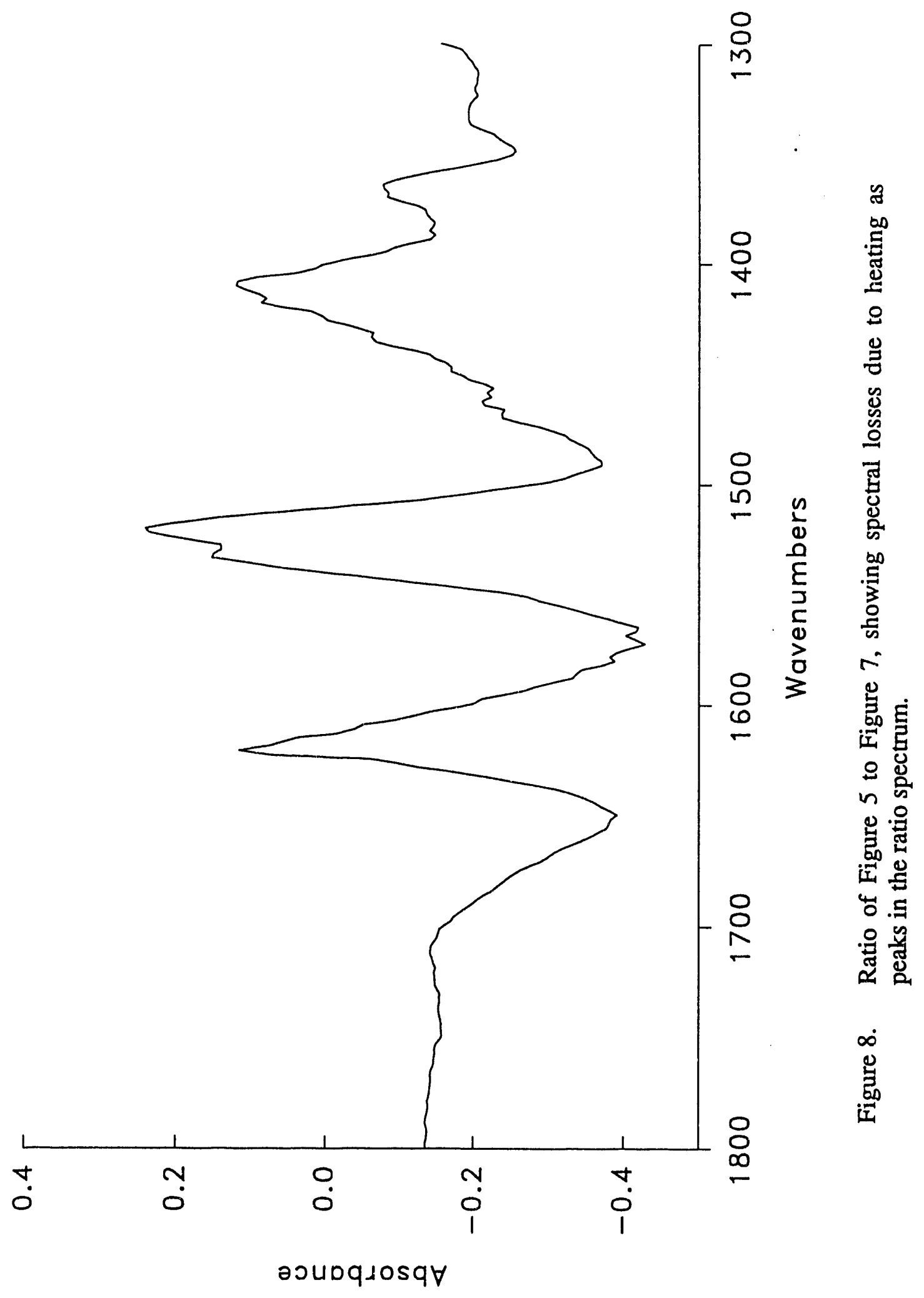




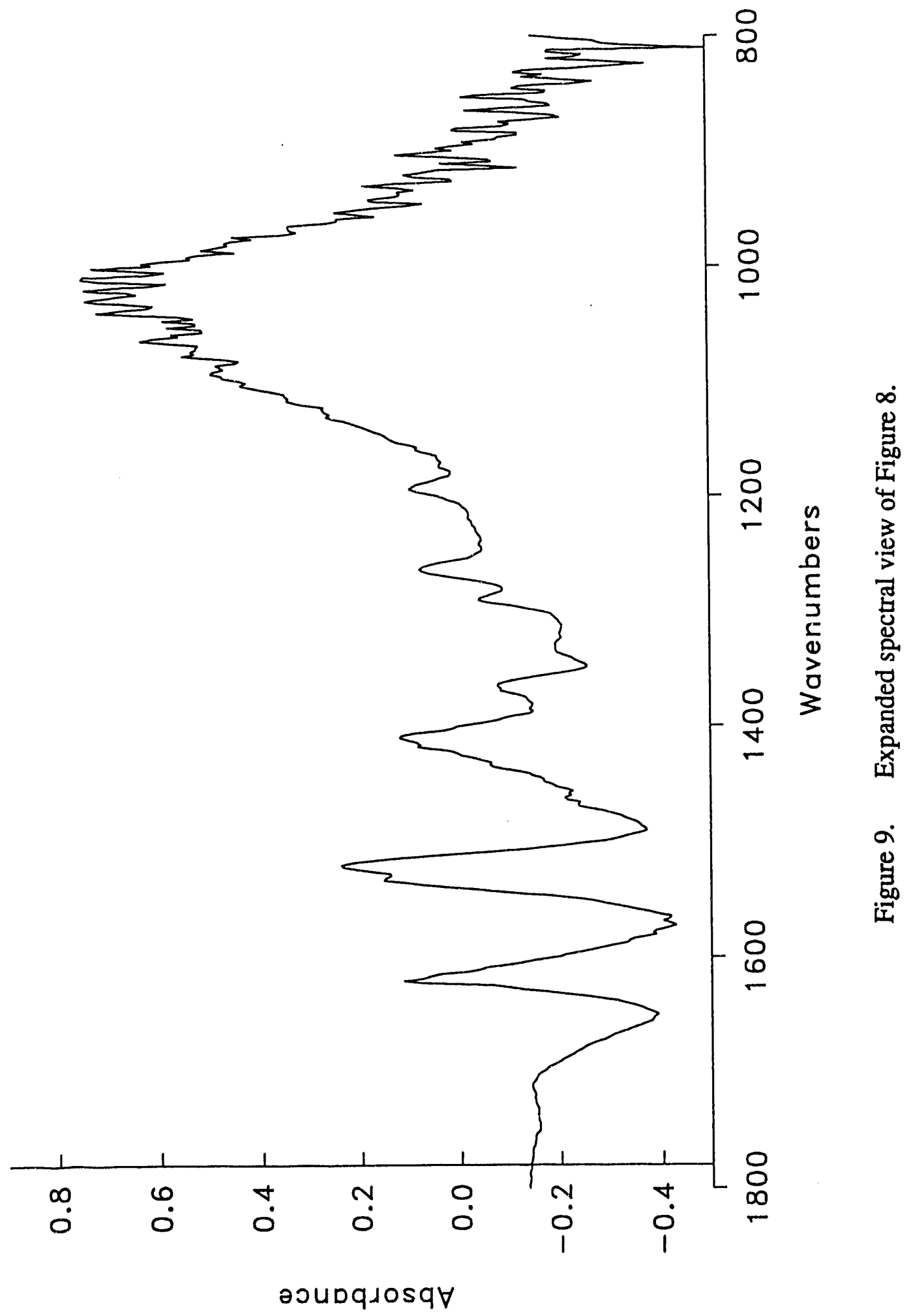


- $37 \mu \mathrm{mol} \mathrm{Mg} / \mathrm{g} \mathrm{Al}_{2} \mathrm{O}_{3} ; 0.15 \mathrm{wt} \% \mathrm{MgO}$

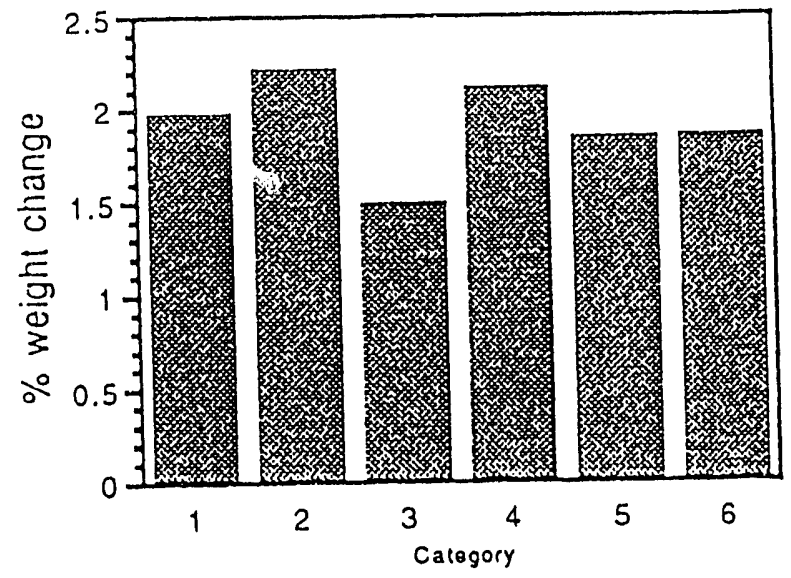

$47 \mu \mathrm{mol} \mathrm{Mg} / g \mathrm{Al}_{2} \mathrm{O}_{3} ; 0.19$ wt\% $\mathrm{MgO}$

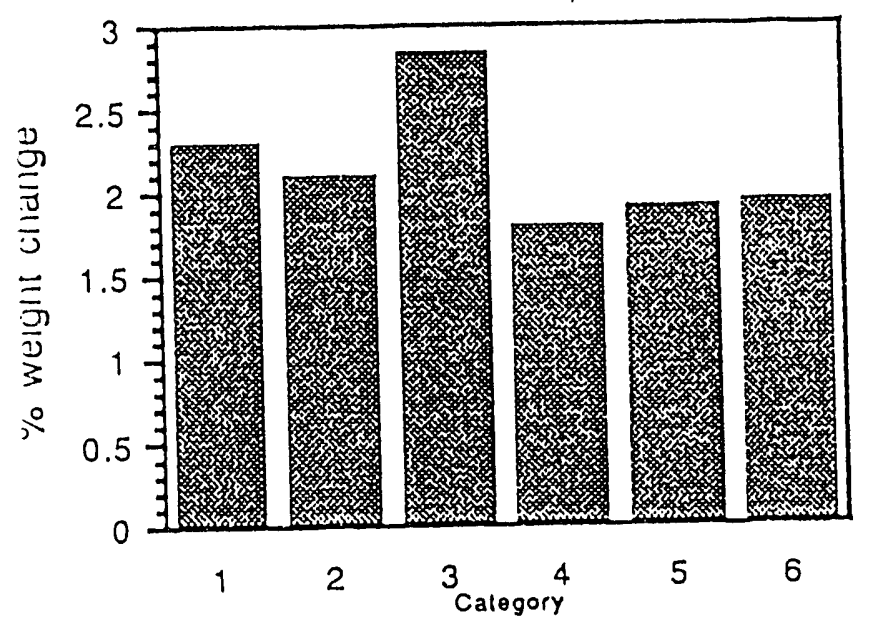

$58 \mu \mathrm{mol} \mathrm{Mg} / \mathrm{g} \mathrm{Al}_{2} \mathrm{O}_{3} ; 0.23 \mathrm{wt} \% \mathrm{MgO}$

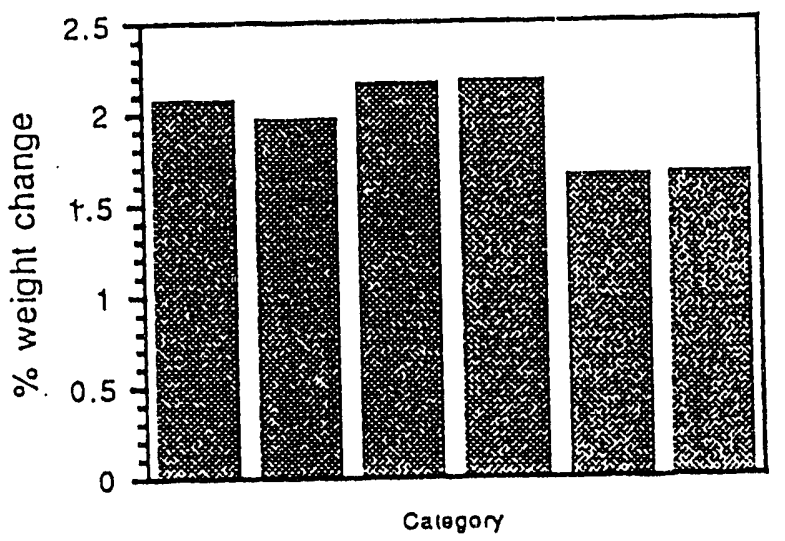

$75 \mu \mathrm{mol} \mathrm{Mg} / \mathrm{g} \mathrm{Al}_{2} \mathrm{O}_{3} ; 0.30$ wt\% $\mathrm{MgO}$

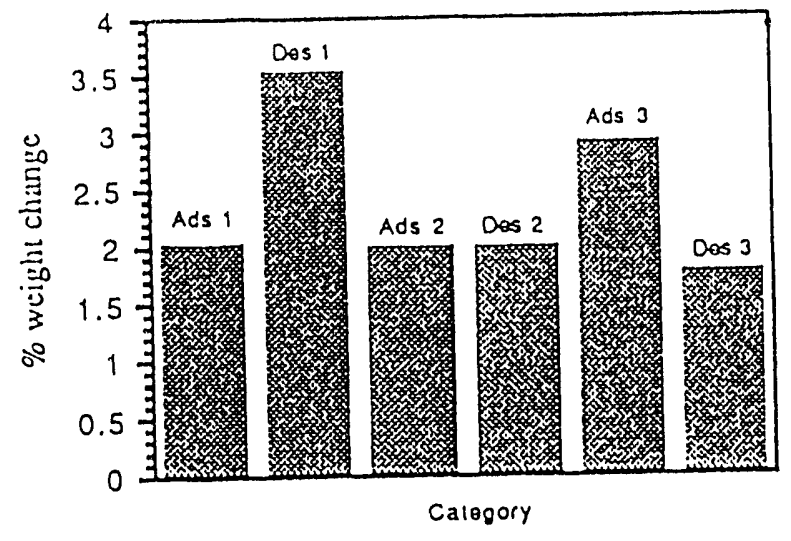

$131 \mu \mathrm{mol} \mathrm{Mg} / \mathrm{g} \mathrm{Al}_{2} \mathrm{O}_{3} ; 0.53 \mathrm{wt} \% \mathrm{MgO}$

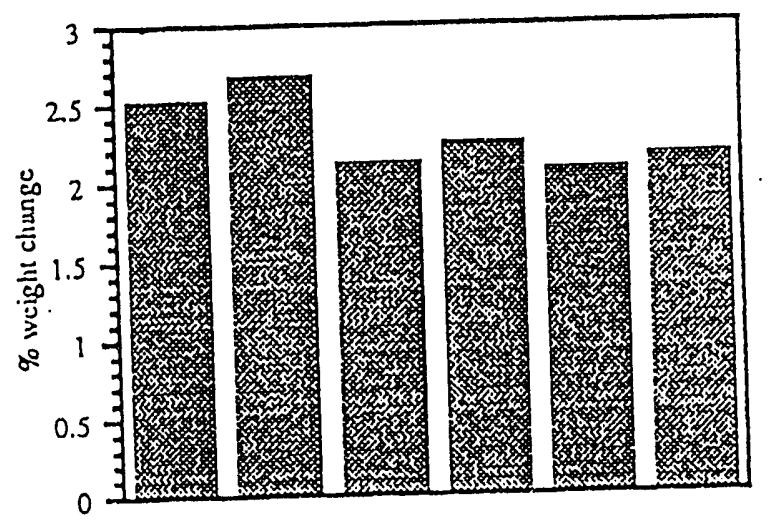

$164 \mu \mathrm{mol} \mathrm{Mg} / \mathrm{g} \mathrm{Al}_{2} \mathrm{O}_{3} ; 0.66 \mathrm{wt} \% \mathrm{MgO}$

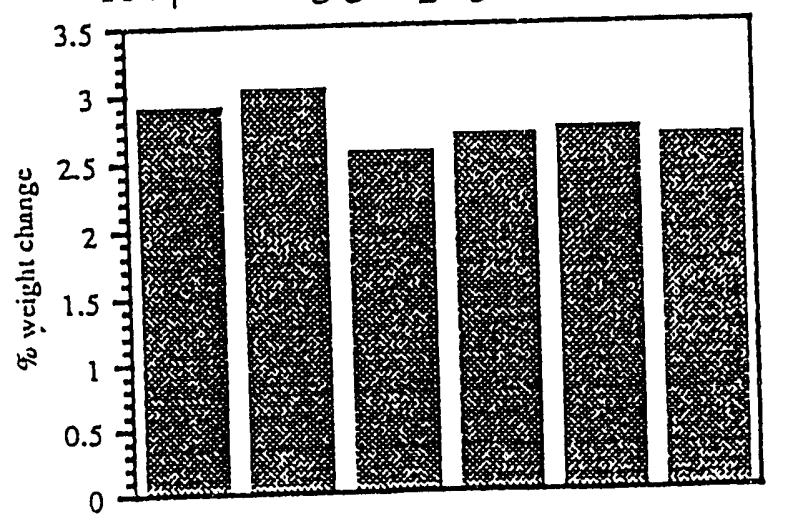

Figure 10. Graphical representation of $\mathrm{SO}_{2}$ adsorption/desorption results for different weight loadings of $\mathrm{Mg}$ on alumina. 


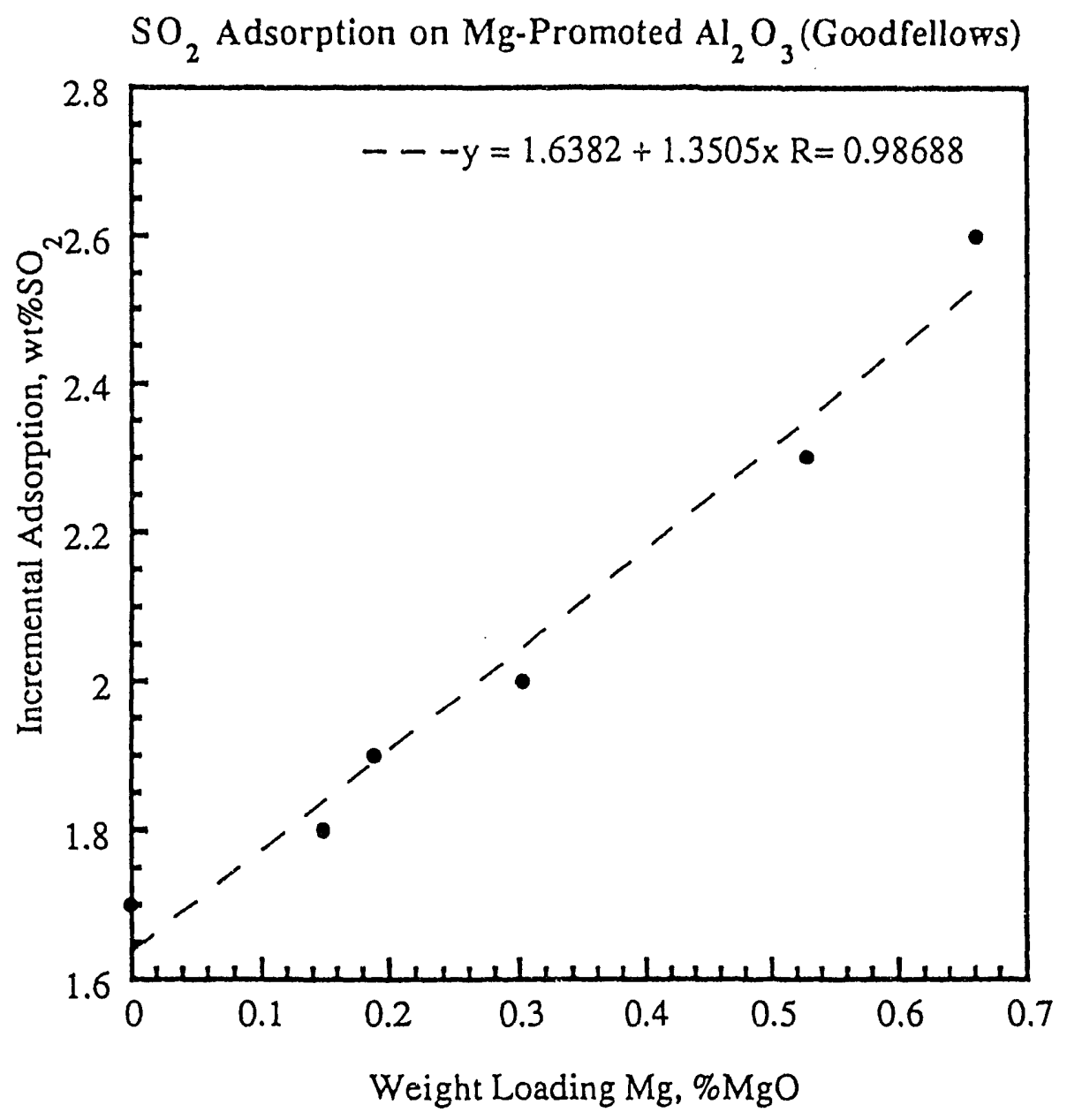

Figure 11. Uptake of $\mathrm{SO}_{2}$ as a function of $\mathrm{Mg}$ loading. 


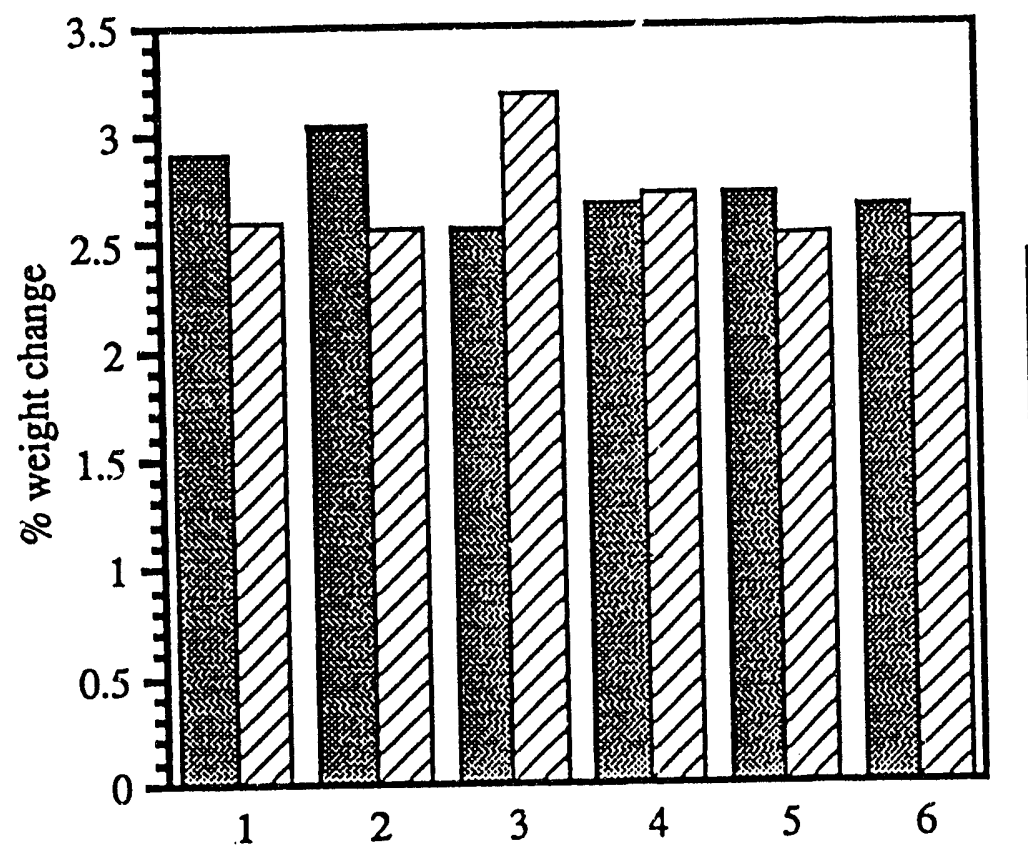

\begin{tabular}{|ll|}
\hline 网 & Nitrogen \\
$\square$ & Oxygen \\
\hline
\end{tabular}

1. First Adsorption

2. First Desorption

3. Second Adsorption

4. Second Desorption

5. Third Adsorption

6. Third Desorption

Figure 12. Graphical representation of $\mathrm{SO}_{2}$ adsorption/desorption results for different adsorption/desorption atmospheres. 


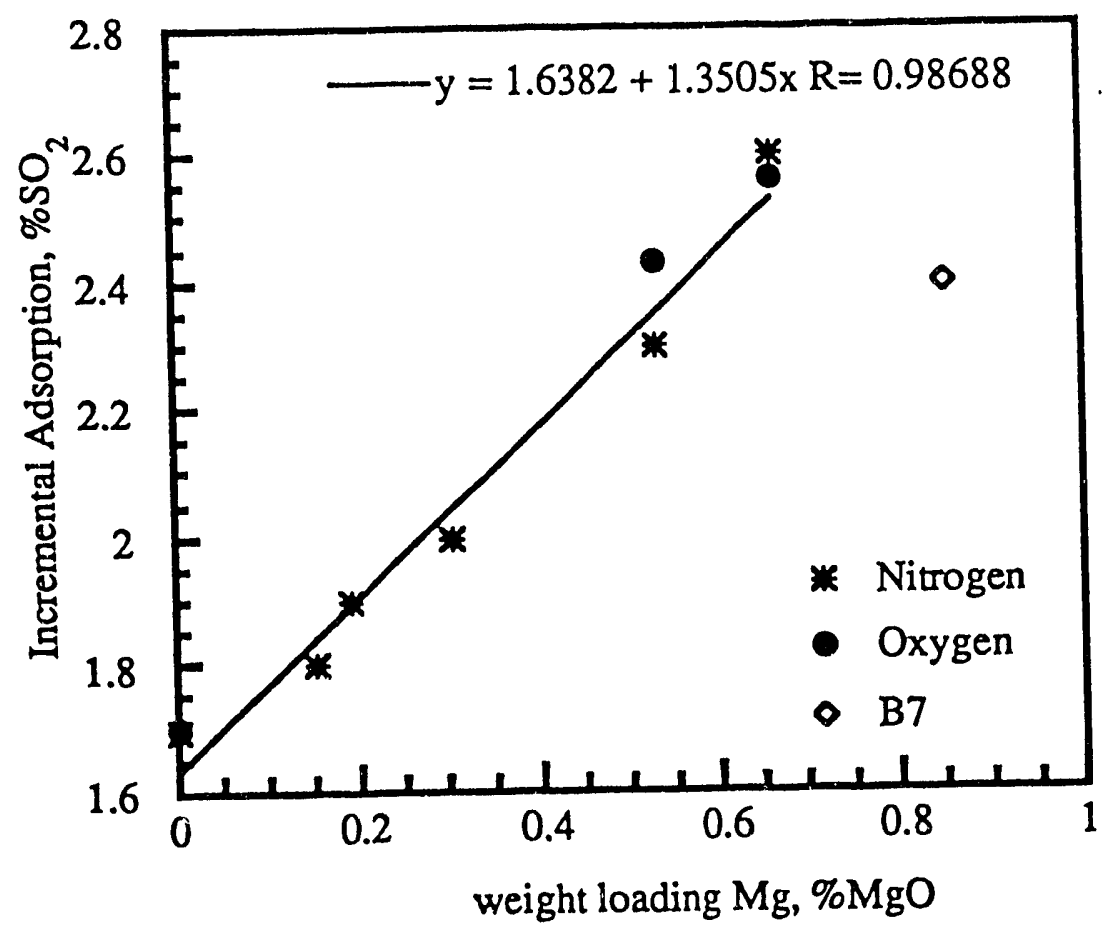

Figure 13. Uptake of $\mathrm{SO}_{2}$ as a function of $\mathrm{Mg}$ loading, including results from aqueous impregnation (B7) and oxygen atmosphere experiments. 


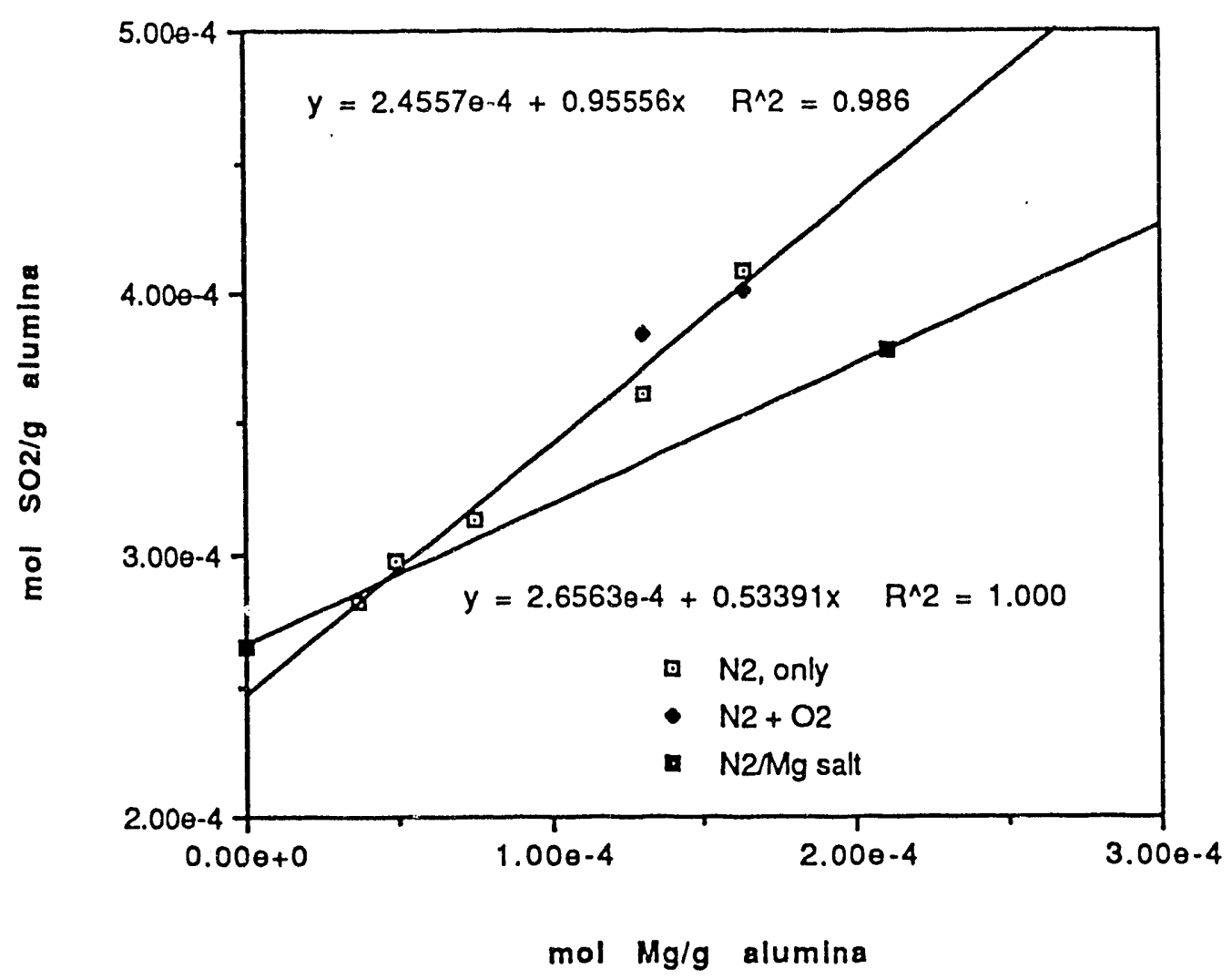

Figure 14. Same as Figure 13, but with units appropriate for comparison of adsorption stoichiometries. 


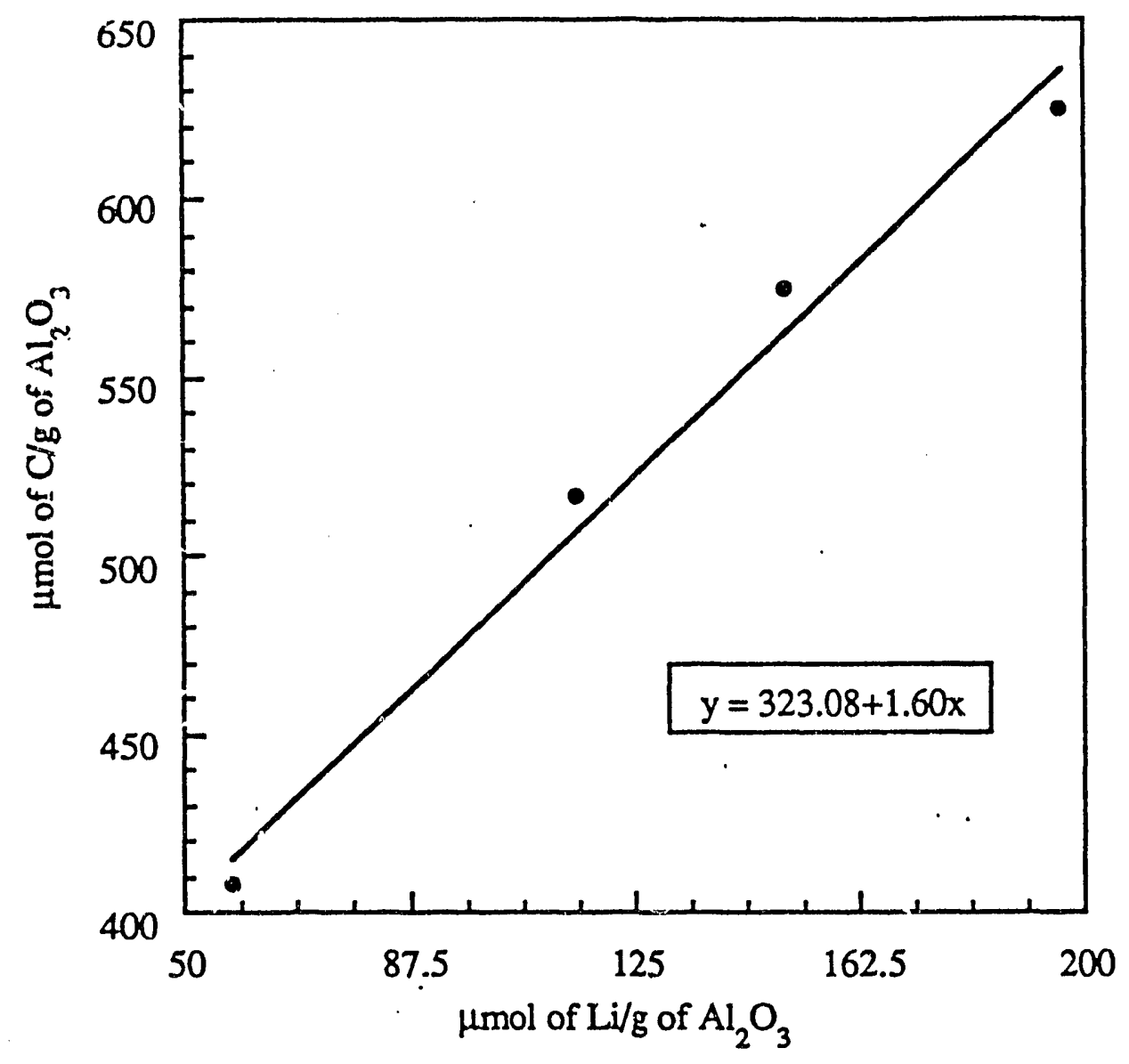

Figure 15. Plot of the measured carbon content vs measured lithium content for the impregnated alurnina samples. 

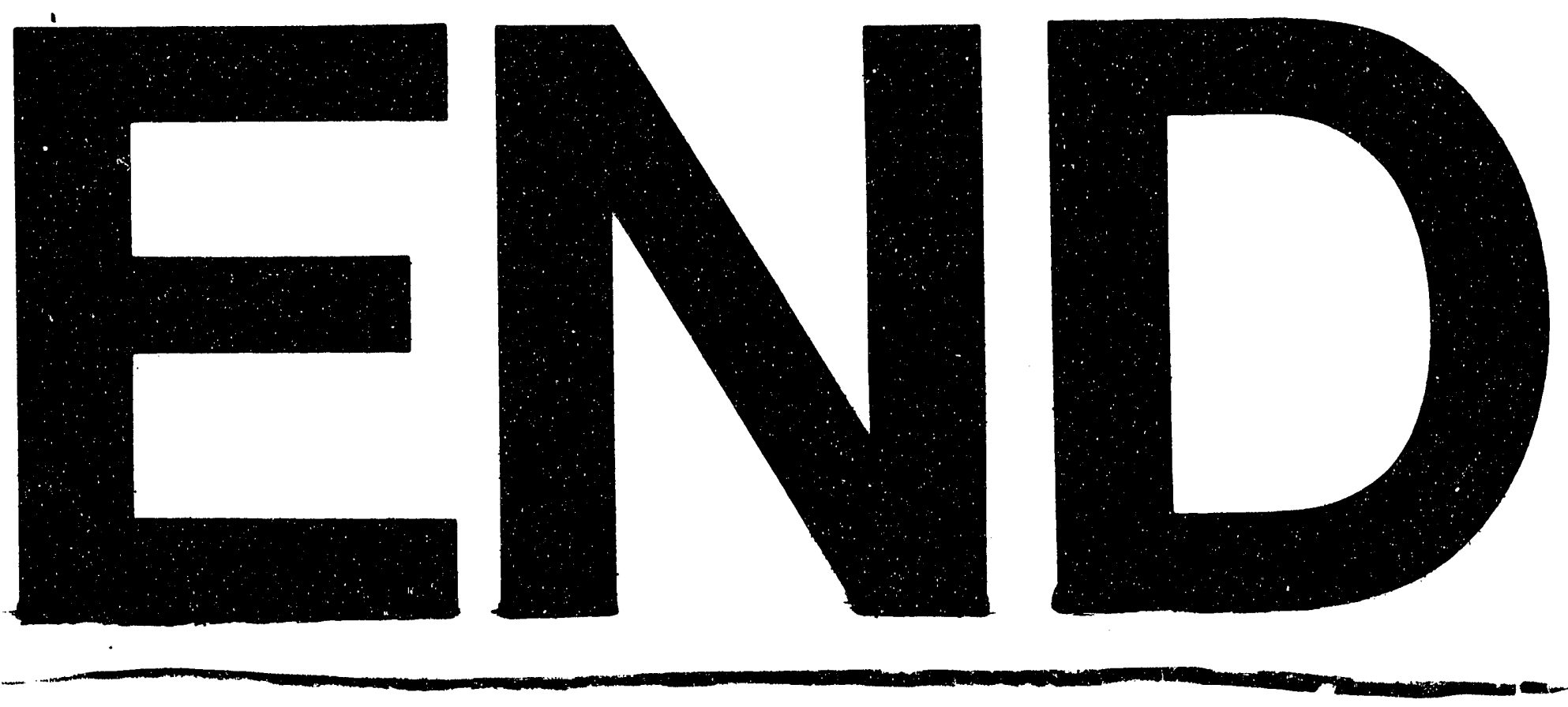
